\title{
Artíalo especial: Obras maestras del arte universal y la medicina: Muerta mimosa tuya quiero ser. Elena Bellamuerte de Macedonio Femandez (1874-1952)
}

Universal art masterpieces and medicine: Mimosa dead I want to be yours. Elena Bellamuerte by Macedonio Fernandez (1874-1952)

Carlos G. Musso \pm

Musso CG. Muerta mimosa tuya quiero ser. Elena Bellamuerte de Macedonio Fernandez (1874-1952). Evid Act Pract Ambul. 94. Jul-Sep.

\section{Macedonio: genio, drama y creación}

En 1920, el escritor Macedonio Fernández pierde a su amada esposa, Elena de Obieta, y dicho fallecimiento deviene un hito fundamental no sólo en su vida personal, sino también en su actividad creadora. A partir de este doloroso acontecimiento, Macedonio desarrolla un originalísimo estilo, desatendiendo las clásicas reglas del lenguaje literario, creando textos insólitos, donde ficción y realidad se fusionan, desintegrando la causalidad, la sucesión de las series temporales y los límites del espacio. De esta manera el autor (cazador) busca detener en la confusa trama de sus escritos (red), el paso de la muerte (presa); resulta entonces que la ecuación se invierte, pues es ahora el hombre (Macedonio) quien atrapa a la muerte, y si bien Elena de Obieta ha fallecido, su alter ego Elena Bellamuerte vivirá por siempre en el limbo que Macedonio con amor ha creado a su medida. Como reza el Cantar de los Cantares "el amor es más fuerte que la muerte".

\section{Ejemplos en el poema}

- El uso no gramatical de las mayúsculas: su función es la de destacar la importancia de la idea encarnada en dicha palabra independientemente de su ubicación en la frase, aquí por ejemplo "Noche" designa a la traumática muerte de su esposa, y "Día" a la felicidad plena que ella significó para él en vida:

"No has de dejarme lejos en la Noche sola dormir la que tu Día fue."

- La aplicación de los verbos trasgrediendo la gramática española: aquí por ejemplo lo esperable sería que hubiera utilizado el verbo "ser" conjugado en presente "esposo de la muerte soy yo", sin embargo lo reemplaza por el verbo "haber" conjugado en pasado "esposo de la muerte hube yo", significando que no es un mero viudo, sino que él ha muerto en vida junto con su esposa.

"Donde Adiós y Jamás a otros esperan esposo de la muerte hube yo."

- El entrecruzamiento informal de roles entre sustantivos y adjetivos a fin de crear una ruptura en el texto que transmita una confusión entre ficción y realidad. Así por ejemplo donde se esperaría: "en la oscuridad dormida estoy", el escribe "en oscuro y dormida soy". Logra así crear un momento en que al desordenarse el tiempo y el espacio, lo eterniza, y disipa así la posibilidad de la muerte, que es su objetivo último:

"Yaciente solitaria, en oscuro y dormida

soy, la que no tuvo en su alma

un consentir posible a saberse olvidada."

\section{La perspectiva macedoniana en la medicina moderna}

Los nombres que se utilizan para designar a las distintas enfermedades constituyen rótulos arbitrarios, aunque validados por su utilidad práctica y por el consenso, los cuales logran segmentar, en porciones humanamente entendibles y manejables, lo que en realidad es una inmensa cadena (continuo) de imbricados procesos fisiopatológicos. Este artilugio lingüístico le ha permitido a generaciones de científicos poder pensar en estos problemas en términos de enfermedades y procurar, a partir de su conceptualización, resolverlos o al menos mitigarlos. Sin embargo, la prolongación de la expectativa de vida junto con el desarrollo de diversas terapéuticas (antibióticos, diálisis, trasplante, etc.) dio lugar a la aparición de nuevos escenarios fisiopatológicos cuyo curso evolutivo y respuesta terapéutica difiere significativamente de los anteriores, de modo que muchas veces los antiguos rótulos les resultan insuficientes. Así por ejemplo, se designa como "dislipidemia" a la presencia a nivel sérico de lípidos en rango elevado, tanto en una persona con función renal normal como en aquella que se encuentra en diálisis crónica, cuando ya se ha demostrado que el tratamiento farmacológico de la dislipidemia posee un impacto en la mortalidad cardiovascular muy distinto en cada uno de estos pacientes. Cabe entonces preguntarse: ¿Merecen ambas entidades designarse con el mismo término de "dislipidemia", o a la dislipidemia del paciente en diálisis le correspondería tener su propia terminología, destacando así su carácter distintivo?, por ejemplo designándola como "dislipidemia-D". Queda claro que aquellos nuevos escenarios fisiopatológicos cuya evolución y respuesta a la terapéutica difieren significativamente de los clásicos, requieren de una expansión y enriquecimiento de la terminología médica heredada, a fin de contribuir de esta forma a generar una mirada médica más precisa y en consonancia con la forma actual de sanar y enfermar.

Recibido el 01/02/2015 y aceptado el 01/03/2015

Referencias

1. Femández M. Poemas. Buenos Aires: Corregidor; 2010

2. Fernández M. Relato, cuentos, poemas y misceláneas. Buenos Aires: Corregidor; 2014

3. Salvador N. Macedonio Femandez creador de lo insólito. Buenos Aires: Corregidor; 2003.

4. Bueno M. Macedonio Femández, un escritor de Fin de Siglo. Genealogía de un vanguardista. Buenos Aires: Corregidor, 2000.

5. Musso CG. We need new terms to better explore emergent clinical settings. Cardiovascular Diabetology. 2014;12:156. 